DIW BERLIN

Discussion

Papers

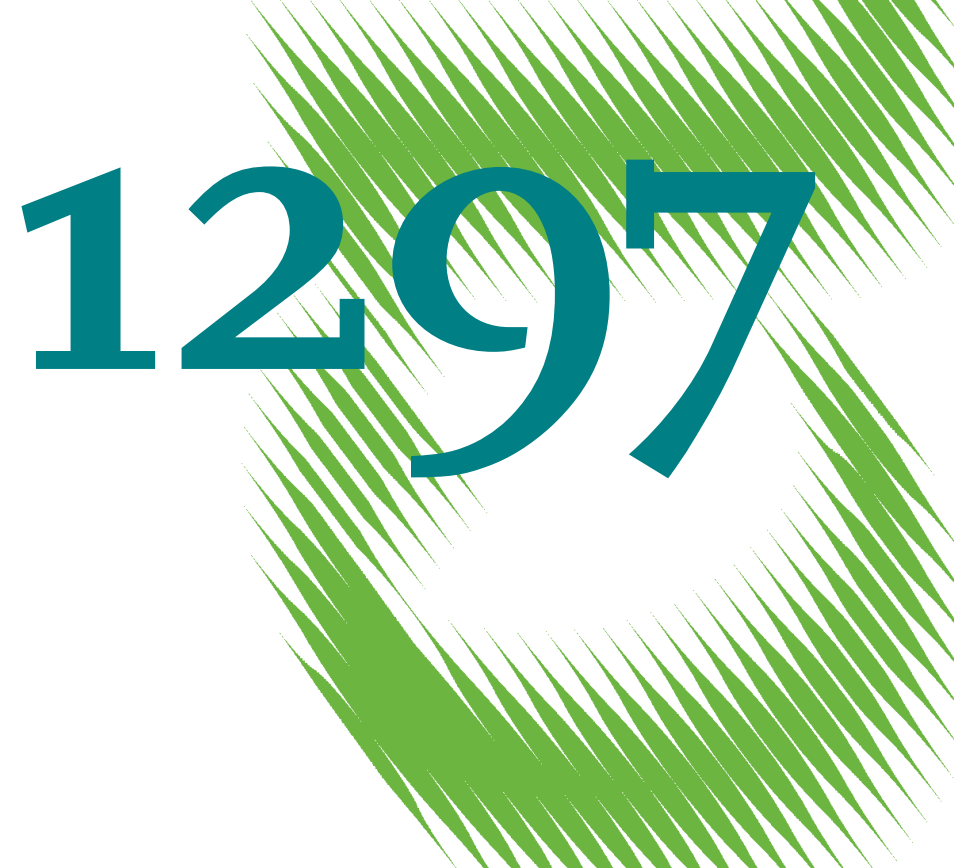

Trick or Treat? -

Maternal Involuntary Job Loss and Children's Non-Cognitive Skills 
Opinions expressed in this paper are those of the author(s) and do not necessarily reflect views of the institute.

IMPRESSUM

(C) DIW Berlin, 2013

DIW Berlin

German Institute for Economic Research

Mohrenstr. 58

10117 Berlin

Tel. $+49(30) 89789-0$

Fax +49 (30) $89789-200$

http://www.diw.de

ISSN print edition $1433-0210$

ISSN electronic edition 1619-4535

Papers can be downloaded free of charge from the DIW Berlin website:

http://www.diw.de/discussionpapers

Discussion Papers of DIW Berlin are indexed in RePEc and SSRN:

http://ideas.repec.org/s/diw/diwwpp.html

http://www.ssrn.com/link/DIW-Berlin-German-Inst-Econ-Res.html 


\title{
Trick or treat? \\ Maternal involuntary job loss and children's non-cognitive skills
}

\author{
Frauke H. Peter*
}

\author{
May 2013
}

\begin{abstract}
Negative effects of job loss on adults such as considerable fall in income have long been examined. If job loss has negative consequences for adults, these may be transferred to their children. But potential effects on children's non-cognitive skills and the related mechanisms have been less examined. This paper uses propensity score matching to analyze maternal involuntary job loss and its potential causal effect on children's non-cognitive skills. Job loss is defined as end of employment either due to plant closure or due to dismissals by employer. Using a rich and representative data set, the German Socio-Economic Panel Study (SOEP), I estimate associations of maternal job loss on child outcomes for preschool children aged five/six and for adolescents aged seventeen. The paper analyses influences on children's socio-emotional behavior and on adolescents' locus of control. The obtained results show that children whose mothers experience an involuntary job loss are more likely to have behavioral problems and are less likely to believe in self-determination.
\end{abstract}

JEL classifications: J13, J63, J65

Keywords: child development, maternal job loss, non-cognitive skills, propensity score matching

\footnotetext{
*German Institute for Economic Research, Mohrenstrasse 58, 10117 Berlin, Phone: +49 30 89789 468, E-mail: fpeter@diw.de

Acknowledgments: I thank the participants at the $17^{\text {th }}$ annual meetings of the Society Labor Economists in Chicago and the participants at the $15^{\text {th }}$ IZA European Summer School in Labor Economics in Buch am Ammersee for valuable comments on earlier drafts of this paper. Special thanks are attributed to my colleague Julia Horstschräer at ZEW in Mannheim for being a "critical friend". I gratefully acknowledges funding from the German Federal Ministry of Education and Research within the framework of the Program for the Promotion of Empirical Educational Research (reference number: 01 JG 0910).
} 


\section{Introduction}

Negative effects of job loss on adults such as a considerable fall in income, persistence of unemployment, bad health or even divorce have been discussed widely in the literature (see for example the studies by Charles \& Stephens 2004, Eliason \& Storrie 2009, Rege et al. 2009). Negative consequences of job loss for adults may transfer to their children. These potential effects on children have been mainly studied for academic performance, for the likelihood of grade repetition, for health, or for earnings (Huff-Stevens \& Schaller 2011, Kalil \& Ziol-Guest 2008, Lindo 2011, Oreopoulos et al. 2008, Rege et al. 2011). But the influence of job loss on children's non-cognitive skills and the related mechanisms have been less examined.

In this paper I address the potential association between maternal involuntary job loss and children's non-cognitive skills. Other studies have analyzed parental job loss and children's outcomes focusing on children's academic achievement or grade repetition (Kalil \& Ziol-Guest 2008, Rege et al. 2011). I hypothesize that a shock - such as an involuntary job loss - experienced by mothers might be more closely related to children's non-cognitive skills, since mothers are in most cases second earners in households and they are still the main caregivers of children. Experiencing an involuntary job loss could negatively influence mothers' emotional balance and thus children's socio-emotional behavior or adolescents' belief in self-determination might be negatively affected.

In order to analyze potential effects of maternal job loss on children's non-cognitive skills, this paper benefits from the vast information on households comprised in the survey data used. The German Socio-Economic Panel Study (SOEP) contains rich information on child characteristics, household characteristics, and maternal characteristics. Firstly, this comprehensive information enables me to estimate potential effects of maternal job loss on children's non-cognitive outcomes using the propensity score method as identification strategy. Although job loss is identified as end of employment due to plant closures or dismissals/layoffs by employer, maternal preferences might bias the influence of job loss on children's outcomes. Secondly, I can address potential mechanisms of maternal job loss using the SOEP.

But in what way are maternal involuntary job loss and children's non-cognitive skills related? By asking trick or treat in the title, the paper implicitly suggests that mechanisms that mediate an effect may be twofold. Meaning maternal job loss could influence child outcomes negatively (as in trick) or positively (as in treat). One mechanism by which maternal job loss negatively affects outcomes of preschool 
children and adolescents is through a drop in income. An income loss may lead to a deterioration of a child's environment. As a result of a decrease in the household income parents might invest less in their children which may impede a child's progress (for example see Eliason 2011, Kalil \& Ziol-Guest 2008). However Kalil \& Ziol-Guest (2008) argue that negative impacts of father's involuntary employment ends depend less on income loss and more on "family dynamics" (Kalil \& Ziol-Guest 2008, p. 500).

Following results of Kalil \& Ziol-Guest (2008) and looking at the vast literature on life satisfaction and unemployment, a potential drop in mothers' mood could be an important mediator by which maternal job loss negatively influences children's non-cognitive skills. The SOEP data used in this paper provides information on maternal life satisfaction and household income before and after maternal job loss. This allows me to roughly assess whether maternal job loss affects children's socio-emotional behavior or adolescents' locus of control via an income loss, via a change in maternal life satisfaction (used as a crude measure of frustration/stress), or via both.

A third possibility through which children's outcomes could be affected is a substitution effect, as mothers who lose their job might substitute their working hours by occupying their time with more time on caring. This effect might be positively associated with children's outcomes, as a mother spends more time with her child than before the job loss supporting her child's development. The quality of mother-child activities cannot be measured directly in the SOEP data. But the data comprise information that allow to assess whether mother-child activities, e.g. reading stories or going to the playground, increase or decrease. Thus, an indirect analysis of this substitution mechanism is possible.

The paper shows that maternal job loss negatively affects children's non-cognitive skills. Children whose mothers experience an involuntary job loss are more likely to have socio-emotional problems and are less likely to believe in self-determination. Using the comprehensive information on maternal and household characteristics of the data, this paper tries to address potential mechanisms of maternal job loss. I show that a decrease of maternal life satisfaction after job loss might be a possible mechanism mediating the influence of job loss on children's socio-emotional behavior.

My work complements the existing literature by analyzing how maternal involuntary job loss affects children's non-cognitive skills. The literature has so far provided scarce evidence on how job loss of parents is linked to children's non-cognitive outcomes. As mothers' job loss is identified based on survey data, the use of propensity score methods enables me to work in a quasi-experimental setting to 
provide robust estimates. In addition, I try to disentangle through which mechanism the potential effect of maternal job loss is mediated. Furthermore, this paper adds to the scarce literature on children's non-cognitive skills and potential distortions influencing this outcome.

The remainder of the paper is structured as follows: Section 2 summarizes the related literature. In Section 3 the data set is described and Section 4 outlines the empirical strategy. In Section 5 the estimation results are discussed. Section 6 comprises several sensitivity analyses before Section 7 concludes.

\section{Related literature}

Besides parental employment affecting child outcomes, studies examine how parental job loss, defined as exogenous income shocks, influences child development (see Oreopoulos et al. 2008, Rege et al. 2011). Yet so far these studies have analyzed parental job loss and child outcomes that are regarded as cognitive outcomes, e.g. academic achievement. The study by Rege et al. (2011) analyses the effect of parental job loss on teenager's academic performance using Norwegian register data. Using a natural experiment approach, they assume that plant closures in Norway between 1999 and 2005 are determined by exogenous shocks and are independent of unobservable determinants of children's school performance. For maternal job loss the authors find that the grade point average of children aged 16 is marginally increased $^{1}$. A study based on Canadian data finds that fathers' job loss from plant downsizing lowers annual earnings of their children compared to those children whose fathers were not laid off (Oreopoulos et al. 2008 $)^{2}$.

Yet not all studies identify exogenous job loss based on a natural experiment approach, researchers also examine involuntary job loss using survey data. Still those few studies based on survey data do not explicitly analyze maternal job loss or non-cognitive skills as child outcome for that matter. Kalil \& Ziol-Guest (2008) estimate children's academic performance as a function of parental employment patterns using US data from the Survey of Income and Program Participation. They determine involuntary job loss due to quitting, dismissal, or illness amongst others (Kalil \& Ziol-Guest 2008, p. 506). They find no significant correlation between mothers' employment experiences and children's grade repetition or

\footnotetext{
${ }_{1}^{1}$ Rege et al. (2011) find that fathers' exposure to plant closure imposes stress on a father. If future employment is discouraging this stress causes children to perform worse in school.

${ }^{2}$ Based on Norwegian employer-employee data, Bratberg et al. (2008) find no effect of fathers' displacement on earnings of children more than ten years after the employment shock.
} 
exclusion/suspension. Huff-Stevens \& Schaller (2011) analyze job loss and children's likelihood of grade repetition based on the same data as Kalil \& Ziol-Guest (2008), yet they define involuntary job ends more narrow focusing only on dismissals or plant closure. Applying child fixed effects they show that exogenous displacements of parents are detrimental for children's academic performance in the short-run ${ }^{3}$.

Furthermore this paper refers to the research on maternal employment and its effect on child outcomes ${ }^{4}$, as this research provides information on the appropriate set of conditioning variables to address selection bias based on propensity score methods, i.e., maternal background characteristics that influence preferences and child outcomes (for further discussion see Section 3.3 in this paper).

\subsection{Mechanisms: how maternal job loss could be linked with children's non-cognitive skills}

Before describing the data more thoroughly, the related literature with respect to potential mediators through which maternal job loss is associated with children's non-cognitive skills is discussed. This paper assumes that job loss affects children's socio-emotional behavior negatively. Meaning that experiencing maternal involuntary job ends during early childhood increases children's socio-emotional problems. Hence children are more likely to have peer problems or emotional problems. Adolescents who experience instability in their family environment due to an exogenous shock might no longer believe that their own action determines success. On the contrary it is likely that maternal job loss, due to plant closure for example, is regarded as something that has happened to the family due to others. Adolescents could thus believe that fate or actions of others determines success in life. Hence these adolescents may become externalizers. Some studies show that having an external locus of control is associated with negative labor market outcomes (Caliendo et al. 2010, Heineck \& Anger 2010 $)^{5}$. But apart from negative labor market outcomes, this context can also be extended to childhood. Adolescents who are likely to have an external locus of control could be less successful in educational attainment, because they might be less proactive or less determined to continue their education after secondary schooling. This in turn affects their labor market

\footnotetext{
${ }^{3}$ Parental job loss significantly increases children's likelihood of grade repetition.

${ }^{4}$ See for example the studies by Baum II (2003, 2004), James-Burdumy (2005), Ruhm (2004. 2008, 2009), Waldfogel et al. (2002)

Caliendo et al. (2010) show that individuals who have an external locus of control are less likely to leave unemployment.
} 
outcomes eventually. Preschoolers with a higher Total Difficulties Score could face problems in school, as they could be less likely to interact with peers or teachers.

An income loss after job loss might be one potential cause of instability at home. Tension due to decreased financial resources between parents could spread to their children, leading to an unstable temper of children affecting their relationship with their peers. This paper hypothesizes that a job loss of mothers may affect child outcomes most likely via a change in maternal emotional balance and not via an income loss. First, because in Germany mothers are often second earners and their job loss might be more closely related to their preferences than to the financial situation of the household. Although mothers face an income loss due to an involuntary job loss, a lot of mothers contribute in addition to their husband/partner to the household income. So an income loss could affect children's outcomes more strongly in a single parent household ${ }^{6}$. In general this could be tested by estimating maternal involuntary job loss and children's non-cognitive skills separately for mothers living with a partner and single mothers. However due to small sample sizes and a small share of single mothers in the data used, this hypothesis cannot be inferred empirically. Second, an income loss as potential mediator of maternal job loss might be less likely, as mothers of preschoolers work less hours, which leads to a minor income loss. Thus, mothers who lose their job may rather be stressed due to a job loss itself, which indirectly affects their bond with their children.

Maternal job loss might decrease a mother's life satisfaction which in turn could deteriorate the emotional stability of her relationship with her child, since a mother might have re-entered the labor market after being dissatisfied with "solely" being a mother (see for example the study on maternal life satisfaction and child outcomes by Berger \& Spiess 2011). A change in parents' emotional balance is closely related to the literature on unemployment and life satisfaction (see for example the work by Clark et al. (2010) or Knabe et al. (2010)). Parents may experience their life less positive due to job loss. In the economic literature a negative effect of unemployment on life satisfaction is identified. Clark et al. (2010) show that regional unemployment for a given level of perceived job security has a negative effect on life satisfaction. Given that, the incidence of job loss which leads to unemployment could affect mothers overall life satisfaction.

\footnotetext{
${ }^{6}$ In Germany 19 percent of families with children under 18 are single parent households (Statistisches Bundesamt 2010). Although the share of single parent families increased since 1996 (14 percent compared to 19 in 2010), this paper argues that other mechanisms than income loss might mediate maternal involuntary job loss.
} 
Apart from maternal life satisfaction being directly related to children's outcomes ${ }^{7}$, it might also be closely related to maternal preferences. Meaning that mothers who are forced to stay at home after an involuntary job loss may be less willing to engage in mother-child interaction. If mothers regard their job as fulfilling and not as sole means to earn money, mothers could be disappointed to be "only" a mother after experiencing a dismissal or plant closure. A job loss thus may also affect the quality of time spent together.

Yet the substitution effect of mothers' time after job loss could also mediate a positive effect of mothers' displacement. If mothers spent more time with their children it could increase children's development. A Norwegian study by Rege et al. (2011) for example finds that mothers' displacement due to plant closure marginally increases children's grade point average at age sixteen. Thus, mothers' supervision, while spending time with their children, who are for example doing homework, seems to have a small but positive effect. However stress or frustration are also associated with job loss and might indirectly aggravate the quality of time spent with children.

Having to substitute working hours in time spent with children might be more difficult for mothers who decided to work instead of being a "housewife". The quality of activities done with children might be mediocre, since mothers might show their discouragement after job loss while supervising their children. The SOEP data used comprise a crude measure of the quality of time spent with children. In the data activities done by mother and child, such as reading a book together or going to the playground, are observed. A change in "reading together" after job loss roughly summarizes either a drop, no change, or even an increase in the "quality" of time. Thus, at least in part I am able to assess whether a job loss and mothers' potential substitution of time has a positive or a negative effect.

\section{Data}

Using data from the German Socio-Economic Panel Study (SOEP), my analysis is based on a representative and rich data set. The SOEP started in 1984 and is an annual household panel ${ }^{8}$ that comprises a series of mother-child questionnaires as well as a youth specific questionnaire. The child-specific modules of the SOEP

\footnotetext{
[Berger \& Spiess (2011) show that higher maternal life satisfaction decreases children's socio-emotional problems. They argue that the positive effect of maternal life satisfaction stems from more responsiveness to the children, which affects the quality of mother-child interactions.

${ }^{8}$ A general overview of the SOEP is given by Wagner et al. (2007), whereas Schupp et al. (2008) and Siedler et al. (2009) describe the mother-child questionnaires used in this paper. Frick \& Lohmann (2010) document the youth questionnaire.
} 
contain detailed information on children, i.e., non-cognitive skills, birth weight, child care usage, school attendance, and grade repetition amongst others. In addition the SOEP has rich information on individual characteristics of children's mothers as well as on family characteristics. The SOEP accumulates information on current household compositions as well as on past formations. Based on this vast data set mothers' probability of involuntary job loss is estimated.

In this paper I restrict the sample of children aged five/six in the SOEP to children whose mothers answered the mother-child questionnaire, whose mothers were 20 years and older at childbirth, who have non-missing information on the measured non-cognitive skills, and whose mothers participated in the survey prior 2003, and therefore have non-missing information prior childbirth. For the implementation of propensity score matching, I determine a point in time at which mother's are observed to lose their jobs. Since mothers are entitled to three years of parental leave in Germany, I assess mothers' working status after a child's third birthday. In period $t>3$ when children are three years and older, I observe whether mothers are working and thus may lose their job. A detailed discussion of variables used for modeling the selection decision is given in the Section 3.3. Thus, the sample used to examine effects of maternal job loss for children aged five/six includes 315 observations of children whose mothers are observed to be working after age three of the child.

In the youth sample of the SOEP, children aged 17 and older are pooled. The sample is restricted to children who are living with their parents, who are born between 1984 and 1993 and thus are 17 years old at the time of the survey, who have non-missing non-cognitive skill information, whose mothers were 20 years and older at childbirth, and whose mothers have reported their employment status during early childhood. Unlike in the preschool sample maternal employment patterns prior childbirth cannot be observed for all birth cohorts, as the household panel started in 1984 and because a lot of households in the SOEP since 2000. Meaning that for those children nearly no information prior to 2000 is included in the SOEP $(\mathrm{N}=1397$ of 3679 adolescents (37.97 percent)). Thus, I have to use another cut-off date to predict mothers' propensity scores. In addition, for some mothers earlier working information coincides with unification and its transition year 1990/1991. A second reason for diverting from the cut-off date used for preschool children is related to children's school careers in Germany. From age ten onwards children transit from primary to secondary school. Thus if I were to use an earlier cut-off date observing an even longer period of time where mothers of adolescents might experience an involuntary job loss, the results could be spurious due to other events. Besides 
mothers of these birth cohorts were more likely to return to work full-time while children were in secondary school ${ }^{9}$. Hence the period during which maternal job loss is observed ranges from age ten until age seventeen of the child. The final sample of adolescents comprises 742 observations of adolescents whose mothers are observed to be working after age ten of their child. Similar to the preschool sample I predict mothers' likelihood of job loss using a vast set of covariates (see Section 3.3 for a detailed discussion).

\subsection{Involuntary job loss}

Involuntary job loss is first and foremost identified as job ending due to plant closure. In the SOEP a job loss is experienced by mothers within a survey year and is reported by stating that they "left a job after December $31^{\text {st }}$ and how this job was terminated" since the last interview. Mothers can choose among eight categories for job ends, including resignation, retirement, suspension, end of temporary contract, or dismissal by employer. Since plant closure occurs less frequent in the data used, I include both, plant closure and layoff experiences, in my analyses as involuntary job loss measure. By adding dismissals to mothers' involuntary job loss, I follow (Huff-Stevens \& Schaller 2011, p. 291) who define job ends based on the following answer categories: "the person was fired or discharged, if the employer was sold or went bankrupt, or if the job loss was due to slack work or business conditions".

Thus, analogue to previous works ${ }^{10}$, this paper considers plant closure as a "truly" exogenous shock whereas layoffs might be partly endogenous. Compared to dismissal by employer a firm closure cannot be caused by maternal behavior. However, I argue that maternal behavior, such as lack of concentration or absence due to sickness of children, which may lead to a dismissal can be partly accounted for in the analyses. First by including child-related characteristics in the estimation of maternal propensity scores and second by including maternal personality traits in the analyses.

In both samples job loss is analyzed by using a comprehensive measure which includes involuntary incidences of job loss, i.e plant closure and dismissal by employer. In the pooled sample of children aged five/six, 6 percent of working mothers lose their job in the observation period, whereas in the pooled sample of children aged seventeen 12 percent of mothers experience an involuntary job loss

\footnotetext{
${ }^{9}$ In 2008, for example, 59 percent of mothers with children below the age of six were employed compared to 70 percent of mothers with children age ten or older (Rübennach 2010$)$.

${ }^{10}$ See among others the studies by Coelli (2011), Huff-Stevens \& Schaller (2011), Kalil \& Ziol-Guest (2008).
} 
(see Table 1). Plant closures as job loss are experienced by 2 percent of mothers of children aged five/six and by 5 percent of mothers of adolescents. The different percentages can also be attributed to a variation in length of the observed time periods, since young children's mothers can loose a job within three years, whereas adolescents' mothers face a seven year time frame and thus have a higher chance of job loss.

Table 1: Distribution of maternal involuntary job loss

\begin{tabular}{lcc}
\hline \hline & \multicolumn{2}{c}{ Mean } \\
& Preschool sample & Adolescence sample \\
\hline & 0.064 & 0.124 \\
Involuntary job loss & 0.020 & 0.051 \\
$\quad$ Plant closure & 0.044 & 0.073 \\
Dismissal by employer & 295 & 742 \\
\hline$N$ & & \\
\hline \hline & Note: Standard deviation in parentheses. SOEP v27 (2001-2010). Own calculations. \\
Samples only include working mothers.
\end{tabular}

\section{$3.2 \quad$ Non-cognitive skills}

In the SOEP non-cognitive skills are measured at different childhood stages using divergent scales. Non-cognitive outcomes often include behavioral, social and emotional skills. This is true for the outcomes used in this paper as well. The socio-emotional behavior measures non-cognitive skills of preschool children, whereas locus of control is used for adolescents' non-cognitive outcome.

Socio-emotional behavior describes a child's behavior in terms of feelings or relationships with family and peers. Goodman (1997) developed the Strength and Difficulties Questionnaire (SDQ), which assesses children's socio-emotional regulation. The SOEP uses a modified version of the SDQ to collect information on preschool children aged five/six. The construction of children's overall socio-emotional behavior accounts for the fact that mothers answer the questionnaire related to children's emotional symptoms, peer problems or conduct problems and others ${ }^{11}$. The reliability of this total difficulties score has also been shown by other studies (see for example Ermisch 2008). In the preschool sample children's SDQ ranges from 0 to 30 with a higher score representing a negative outcome of the child, e.g. having peer problems. In addition children can be grouped in different behavioral categories: normal, borderline, and abnormal. A child's behavior falls

\footnotetext{
${ }^{11}$ Information on the reliability and construction of the SDQ, as well as the categorization into different behavioral groups can be found at http://www.sdqinfo.org
} 
into the category "normal" if the Total Difficulties Score is $\leq 13$, whereas a child's behavior is classified "abnormal" if the Total Difficulties Score is $\geq 17$. If a child's Total Difficulties Score is $\geq 14$ and $\leq 16$ her behavior belongs to the category "borderline"12.

Locus of control is the non-cognitive outcome in the adolescence sample based on the concept developed by Rotter (1966). The locus of control is part of the youth questionnaire since 2001 and adolescents report on a scale from 1 (completely disagree) to 7 (completely agree) regarding "what happens in life depends on me" or "what you achieve is a matter of luck". Factor analysis is used to extract two factors determining whether adolescents believe that their life depends on their own action (internal locus of control) or whether they believe that life is determined by others (external locus of control). In this paper the analyses focus on internal locus of control, since children's belief may be altered by experiencing maternal involuntary job loss. Adolescents may perceive an involuntary job end of their mother as unfair and imposed, which may change their idea of "everything is possible as long as you work hard". ${ }^{13}$

A first descriptive comparison between mothers who lose their job and mothers who keep their job shows that the mean of preschoolers' total difficulties score differs by 3 score points between job loss and no job loss (see Table 2). This difference is statistically significant and hinges towards a potential negative relationship between maternal involuntary job loss and children's socio-emotional behavior: the higher the total difficulties score the higher a child's socio-emotional problems. For adolescents' internal locus of control the difference between children who experience maternal job loss and those whose mothers keep their job is less statistically significant. Yet, the mean of internal locus of control of adolescents exposed to maternal job loss is below zero indicating a likelihood to belief less in self-determination. Thus, a first glance at the descriptive association suggests that there might be negative effects on children's non-cognitive skills when a job loss occurs, although the difference between adolescents' internal locus of control is marginally statistically different from zero.

\footnotetext{
${ }^{12}$ Within the preschool sample 73 percent are in the group "normal", 12 percent in "abnormal" and the remaining 15 percent in "borderline". The sample mean of the total difficulties score is 10.26 .

${ }^{13}$ Thus, maternal job ends could decrease children's factor score, falling below the mean of zero indicating an external locus of control "loading".
} 
Table 2: Distribution of maternal involuntary job loss and children's non-cognitive skills

\begin{tabular}{|c|c|c|c|c|}
\hline & \multicolumn{4}{|c|}{ Mean } \\
\hline & All & Job loss & No job loss & t-ratio \\
\hline \multicolumn{5}{|l|}{ Preschool sample } \\
\hline Total difficulties score & 9.85 & 12.60 & 9.66 & $-2.03^{* *}$ \\
\hline Normal & 0.78 & 0.60 & 0.79 & $-1.72^{*}$ \\
\hline Borderline & 0.12 & 0.20 & 0.12 & -0.96 \\
\hline Abnormal & 0.10 & 0.20 & 0.09 & -1.33 \\
\hline$N$ & 230 & 15 & 215 & \\
\hline \multicolumn{5}{|l|}{ Adolescence sample } \\
\hline Internal locus of control & -0.004 & -0.185 & 0.019 & $1.54^{*}$ \\
\hline External locus of control & -0.064 & 0.055 & -0.079 & 1.09 \\
\hline$N$ & 560 & 64 & 496 & \\
\hline
\end{tabular}

\subsection{Description of observables}

The choice of observables, i.e., relevant characteristics used to match treated and untreated individuals, is based on other empirical studies which investigate maternal employment and child well-being. These variables are likely correlated with maternal involuntary job loss and children's non-cognitive skills ${ }^{14}$. Using rich and representative survey data (SOEP) allows me to include all observables found to be good predictors of maternal job loss.

In this paper I utilize a regression-adjusted matching approach as preferred model specification which requires to control for all conditioning variables in the post-matching estimations (see Stuart 2010). However some child or family background characteristics measured after treatment are relevant variables related to children's non-cognitive skills. Hence apart from including the conditioning variables in the estimations, regional unemployment rates, child's gender and migration background, and maternal personality traits are used as additional explanatory

\footnotetext{
${ }^{14}$ Conditioning variables are based on the following studies: Berger et al. (2005), Hill et al. (2005), Huff-Stevens \& Schaller (2011), James-Burdumy (2005), Ruhm (2008, 2009) and Baum II (2003).
} 
variables in the preschool sample (see Table A.1 in Appendix). These variables are known to be predictive of children's socio-emotional behavior. Small sample sizes restrict not only the set of conditioning variables but also the used covariates included in the post-matching analyses (see Stuart 2010). In the adolescence sample I use as additional control variables regional unemployment rates, living in East Germany, maternal education, partner present, maternal working hours, number of children $<16$ living in the household, logarithmic household income, and maternal personality traits (see Table A.2 in Appendix).

As crude approximation of maternal unemployment duration, I control in all regression analyses for regional unemployment rates which capture the rigidity of the local labor market of mothers. Analyzing maternal job loss and its potential influence on child outcomes requires to asses how long mothers stay unemployed in the subsequent periods. The duration of unemployment is strongly linked to life satisfaction and overall well-being of mothers through which job loss might affect child outcomes (Clark et al. 2010, Knabe et al. 2010).

\section{Empirical strategy}

The goal of this paper is to identify an impact of a given treatment on children's non-cognitive skills. The association of maternal involuntary job loss and children's non-cognitive skills can be summarized by the following reduced form equation, where $S_{i j}$ comprises non-cognitive outcome of child $i$ at age $j, J O B L_{i j}$ is a variable capturing involuntary job loss, $X_{i j}$ represents our measured covariates and $v_{i j}$ is an error term.

$$
S_{i j}=\beta_{i j} J O B L_{i j}+\gamma_{i j} X_{i j}+v_{i j}
$$

The coefficient of interest is $\beta_{i j}$ and it will render causal estimates if the following assumptions are satisfied. The estimates of $\beta_{i j}$ are "true" if maternal job loss is uncorrelated with children's non-cognitive outcomes, i.e., $E\left(v \mid J O B L_{i j}\right)=0$. Estimating Equation 1 yields unbiased estimates in case there is no correlation of involuntary job loss with the error term $v_{i j}$ and thus job loss is exogenous with respect to non-cognitive skills. But since maternal involuntary job loss is related to maternal preferences, selectivity may bias the OLS estimates of $\beta_{i j}$.

In a seminal paper Rosenbaum \& Rubin (1983) define that the probability of receiving treatment (here involuntary job loss) can be summarized as a vector of observed characteristics, called propensity score. And matching based on this propensity score can remove selection bias. Predicting mothers' propensity score 
implements a "random sample", where mothers who work and lose a job do not differ from mothers who work and keep their job in terms of observables, e.g. education, income, or marital status amongst others. So far propensity score matching has been mainly applied for evaluating participation in job training programs (see the work by Ashenfelter 1978, Dehejia \& Wahba 2002, Heckman et al. 1997, LaLonde 1986). Yet the empirical literature increasingly uses propensity score matching to account for various selection biases. For example Jiang et al. (2010) estimate the effect of breast feeding on child cognitive outcomes using propensity score matching, or Eliason (2011) analyzing job loss effects on income, and Gebel (2009) uses propensity score matching to estimate the probability of fixed-term contracts at labor market entry using data from the German Socio-Economic Panel Study.

\subsection{Propensity score methods}

In order to predict maternal propensity scores, observables that predict mothers' job loss have to be identified in the data. In the preschool sample maternal probability of job loss is observed after a child's third birthday. The data used in this paper consists only of those children whose mothers have the "most complete" information on preferences, background characteristics and employment behavior. Thus, only those mothers who can be observed before childbirth are utilized in the early childhood analyses. For the adolescence sample also only children with mothers providing longitudinal information on observables are included in the analyses. Thus, mothers' probability of job loss is predicted after age ten of the child, as it is discussed in the previous section (see Section 3).

\subsubsection{Propensity score matching}

Propensity score matching (Rosenbaum \& Rubin 1983, 1984) is a well-established method to correct selection bias. It is a quasi-experimental approach, comparing outcomes of those who are "treated" to those who are "untreated", simulating a random sample design. Similar to ordinary least squares, propensity score matching relies on the assumption that selection is based on observable characteristics. By using a rich set of variables predicting mothers' likelihood of job loss after age three or age ten respectively, this paper assumes that all relevant information related to maternal job loss can be observed (for an overview of application of matching see Caliendo \& Kopeinig 2008). The assumption that selection only exists on observables is known as conditional independence assumption (CIA). Under the conditional 
independence assumption, the outcome variable - children's non-cognitive skills - and maternal job loss, i. e. exposure to treatment, are independent given characteristics X. Given the data quality at hand, I argue that the analyses in this paper are able to meet this requirement and that relevant observable characteristics that affect mothers' job loss are accounted for.

$$
Y_{1}, Y_{0} \perp D \mid X
$$

Following Rosenbaum \& Rubin (1983) mothers' probability of job loss is predicted based on the relevant $X_{s}$ obtaining a comprehensive measure of all covariates for each person, i.e., the propensity score: $P(D=1 \mid X)=P(X)$, where X represents the set of observed maternal characteristics as well as relevant child and household characteristics, D summarizes the "treatment condition", here whether maternal involuntary job loss after age three or age ten of the child respectively is experienced $(\mathrm{D}=1)$ or not $(\mathrm{D}=0)$, and $P(X)$ is the estimated propensity score.

A second requirement is the common support condition, which implements that a match between mothers of the treatment group and those of the control group is obtained. By applying this restriction those children whose mothers do not overlap with regards to the relevant observables are discarded from the analysis.

$$
0<P(X)<1, \forall X
$$

Expression 3 simply states that the sample does not consist of only working mothers who keep their job $(P(X)=0)$ or of only working mothers who experience an involuntary job loss $(P(X)=1)$ for all given $X_{s}$.

After predicting mothers' propensity score, the observations are matched based on the obtained $P(X)$. All observations who do not comply with the overlap condition are discarded from the sample. Hence the sample used for examining maternal involuntary job loss consists only of those working mothers who have a balanced match based on the same characteristics set $X$. Kernel matching is used to obtain a balanced sample. ${ }^{15}$

Different matching techniques can be applied such as "nearest neighbor (NN) matching", "caliper matching", or "kernel matching". NN matching simply chooses the mother of the comparison group who is identical to the mother of the "treatment" group based on the closeness of their propensity scores. The nearest neighbor technique renders bad matches if the "best" fit in the control group is far away.

\footnotetext{
${ }^{15}$ Matching is implemented in Stata11 using the program psmatch2 provided by Leuven \& Sianesi (2003).
} 
In order to prevent bad matches a tolerance level can be imposed. This tolerance level defines a maximum propensity score distance referred to as caliper. Applying caliper matching may improve the "quality" of the match, but only if the correct tolerance level is chosen beforehand - a choice which is very difficult to make (Smith \& Todd 2005).

In contrast to nearest neighbor and caliper matching, the kernel matching method uses weighted averages of those mothers in the control group depending on the differences in the propensity score (see for an in depth discussion: Imbens 2000, Stuart 2010). Whilst the usage of nearly "all" untreated mothers is an advantage, it may also cause bad matches ${ }^{16}$. In this paper mothers who lose their job are matched with "similar" mothers who keep their job based on kernel matching using the Epanechnikov distribution and a bandwidth of 0.06 to obtain a balanced sample. In the Appendix summary tables depict the balance of the used $X_{s}$ between treatment and control group before and after matching (see Table A.3 and A.4).

After matching mothers on their propensity score the average treatment effect of the treated (ATT) can be estimated. The ATT renders estimates of the difference in child outcomes between treatment and control group due to involuntary job loss. Equation 4 shows the estimation of the ATT using a regression-adjusted matching approach, where a matching-specific weight $W_{i, j}$, in this paper obtained from kernel matching, is used in the analysis. The regression-adjustment method avoids further potential bias if matching is not exact.

$$
A T T=\sum_{i \in T} W_{i}\left[\left(Y_{1 i}-x_{i} \hat{\beta}\right)-\sum_{j \in C} W_{i, j}\left(Y_{0 j}-x_{j} \hat{\beta}\right)\right]
$$

In Equation 4, the symbols $\mathrm{T}$ and $\mathrm{C}$ stand for $T=$ treatment group and $C=$ control group respectively. $W_{i, j}$ represents a matching-specific weight which is the weight placed on individual $j$ to be comparable to individual $i^{17}$. The weight $W_{i, j}$ includes values obtained from kernel matching for the control group of each treated $i$ :

$$
W_{i, j}=\frac{G\left(\frac{P_{i}-P_{j}}{b_{n}}\right)}{\sum_{j \in(d=0)} G\left(\frac{P_{i}-P_{j}}{b_{n}}\right)}
$$

where $G($.$) is a kernel function, e.g. Gaussian or Epanechnikov, and b_{n}$ is a bandwidth parameter.

\footnotetext{
${ }^{16}$ Kernel matching requires a decision on the kernel function and on a bandwidth parameter. The former requirement is less important compared to the latter (Caliendo \& Kopeinig 2008).

${ }^{17} W_{i}$ reweights the treated to obtain their outcome.
} 


\subsubsection{Propensity score weighting}

Beside matching on the propensity score, the average treatment effect of the treated can also be identified by propensity score weighted regressions (see Hirano \& Imbens 2001). Propensity score weighting weights the outcomes of untreated mothers with the inverse of the estimated propensity score $(P(X))$. A critical aspect of using the estimated propensity score as weight is its sensitivity to large estimated propensity scores, since these large values receive a larger weight. This problem decreases with sample size as each observation is less relevant for estimating the coefficient of interest. However, the overall sample size of the samples used in this paper are relatively small. Nonetheless I argue that I have a large enough number of untreated mothers compared to the treatment group. And by restricting the post estimations to the common support area, the problem of "large propensity score values" should have only a minor impact. To estimate the ATT the regression of non-cognitive skills on involuntary job loss is weighted by assigning $w=1$ to mothers who lose their job $(D=1)$, and $w=\frac{1}{(1-P(X))}$ to mothers of the control group $(D=0)$. By weighting the estimated regression, omitted variable bias can be corrected ${ }^{18}$. I apply propensity score weighting as an alternative to matching.

\section{Results}

The results are presented in three steps: (1) the OLS estimates, i.e., regressing maternal job loss on children's non-cognitive skills, then the results obtained from (2) propensity score weighting are shown, and thirdly results from (3) regression-adjusted propensity score matching ${ }^{19}$ are displayed. For example in Table 3 in column 2 the estimates of the average treatment effect on the treated (ATT) using propensity score weighted regression are reported and in column 3 of Table 3 those of the ATT using regression-adjusted propensity score matching. The model depicting OLS simply shows whether the propensity score method compared to an ordinary least squares analysis which includes prior job loss information ("OLS complete") of mothers is more efficient. In a small sample OLS "complete" may be less efficient, e.g. including prior treatment covariates could lead to larger standard errors than for estimates based on the propensity score methods. In all tables only

\footnotetext{
${ }^{18}$ Berger et al. (2005) argue that using the propensity score as weight depends, similar to the conditional independence assumption (CIA), on the specification of observables used to correct selection bias.

${ }^{19}$ The estimates in the matched sample are obtained after applying kernel matching.
} 
the coefficient of the explanatory variable of interest is depicted: involuntary job loss.

\subsection{Involuntary job loss and non-cognitive skills of preschoolers}

In Table 3 the results of involuntary job loss affecting children's socio-emotional behavior are presented. Maternal involuntary job loss is significantly correlated with children's socio-emotional behavior. Using regression-adjusted propensity score matching renders the estimates displayed in column 3. Including the same controls as in the OLS estimation the negative effect on children's total difficulties score remains statistically significant accounting for selection bias. This effect is negative since an increase in the score implies an increase in a child's likelihood of having "behavioral problems". Accounting for selection bias yields a significant positive effect of maternal involuntary job loss: A child's total difficulties score increases by 3 score points, which "lifts" the mean child closer to "abnormal" behavior. The findings in column 2 compared to column 3 suggest that estimating the average treatment effect of the treated using propensity score weighted regression is slightly less efficient as the standard errors are smaller in column 3. The overall negative effect of involuntary job loss on non-cognitive skills remains.

Table 3: Estimation of socio-emotional behavior and maternal involuntary job loss (preschool sample)

\begin{tabular}{|c|c|c|c|}
\hline & \multicolumn{3}{|c|}{ Socio-emotional behavior } \\
\hline & $\begin{array}{c}\text { "OLS complete" } \\
(1) \\
\end{array}$ & $\begin{array}{c}\text { PS weighting } \\
(2) \\
\end{array}$ & $\begin{array}{c}\text { Regression-adjusted } \\
\text { PS matching } \\
(3) \\
\end{array}$ \\
\hline Involuntary job loss & $\begin{array}{c}2.916^{*} \\
{[1.6113]}\end{array}$ & $\begin{array}{c}2.918^{*} \\
{[1.6184]}\end{array}$ & $\begin{array}{l}3.090^{* *} \\
{[1.2714]}\end{array}$ \\
\hline $\begin{array}{l}N \\
R^{2}\end{array}$ & $\begin{array}{c}230 \\
0.147\end{array}$ & $\begin{array}{c}230 \\
0.145\end{array}$ & $\begin{array}{c}230 \\
0.374\end{array}$ \\
\hline
\end{tabular}

Robust standard errors in second row, ${ }^{*} p<0.10,{ }^{* *} p<0.05,{ }^{* * *} p<0.01$. PS=propensity score. Note: All models control for regional unemployment rate, child's gender (female $=1$ ), and child's migration background beside the variables used to predict maternal propensity scores. Own calculations, SOEP v27 (2008-2010).

However, propensity score matching assumes that selection is only based on observables and does not account for unobserved heterogeneity. Children's non-cognitive skills may be correlated with maternal non-cognitive skills which in turn may be affected by an involuntary job loss. Thus, in another specification 
I control for potential unobserved heterogeneity between the matched mothers by including maternal personality traits in my analysis. Controlling for mothers' personality renders the same estimates of maternal involuntary job loss on children's socio-emotional behavior using "OLS complete", propensity score weighting, or regression-adjusted matching (see Table 4). The effect size drops from 3 score points to 2.3 score points in the preferred specification (see column 3 of Table 4).

Table 4: Estimations of socio-emotional behavior under inclusion of maternal personality traits (preschool sample)

\begin{tabular}{|c|c|c|c|}
\hline & \multicolumn{3}{|c|}{ Socio-emotional behavior } \\
\hline & $\begin{array}{c}\text { "OLS complete" } \\
(1) \\
\end{array}$ & $\begin{array}{c}\text { PS weighting } \\
(2) \\
\end{array}$ & $\begin{array}{c}\text { Regression-adjusted } \\
\text { PS matching } \\
(3) \\
\end{array}$ \\
\hline Involuntary job loss & $\begin{array}{c}2.640^{*} \\
{[1.5432]}\end{array}$ & $\begin{array}{c}2.627^{*} \\
{[1.5439]}\end{array}$ & $\begin{array}{l}2.284^{* *} \\
{[1.1253]}\end{array}$ \\
\hline Maternal personality traits & $\checkmark$ & $\checkmark$ & $\checkmark$ \\
\hline$N$ & 229 & 229 & 229 \\
\hline$R^{2}$ & 0.174 & 0.175 & 0.435 \\
\hline
\end{tabular}

\subsection{Involuntary job loss and non-cognitive skills of adolescents}

Table 5 summarizes the relationship of adolescents' internal locus of control and maternal job loss. Using OLS with prior information ("OLS complete") as it is depicted in column 1 indicates that maternal job loss decreases the likelihood of believing in self-determination by 23.1 percent of a standard deviation. The results based on propensity score weighting show also a marginal significant average treatment effect of the treated (see column 2 of Table 5). Meaning that adolescents whose mothers experience plant closure or dismissal by employer are less likely to believe that working hard or striving for ones own success helps to achieve ones goals. An involuntary job loss decreases adolescents belief in self-determination by $1 / 5^{\text {th }}$ of a standard deviation. This effect remains stable and only decreases slightly in size when using regression-adjusted propensity score matching (by 22.4 percent of a standard deviation, see column 3). 
Table 5: Estimation of internal locus of control and maternal involuntary job loss (adolescence sample)

\begin{tabular}{|c|c|c|c|}
\hline & \multicolumn{3}{|c|}{ Internal locus of control } \\
\hline & $\begin{array}{c}\text { "OLS complete" } \\
(1)\end{array}$ & $\begin{array}{l}\text { PS weighting } \\
(2) \\
\end{array}$ & $\begin{array}{c}\text { Regression-adjusted } \\
\text { PS matching } \\
(3) \\
\end{array}$ \\
\hline Involuntary job loss & $\begin{array}{l}-0.231^{*} \\
{[0.1356]}\end{array}$ & $\begin{array}{l}-0.225^{*} \\
{[0.1362]}\end{array}$ & $\begin{array}{l}-0.224^{*} \\
{[0.1158]}\end{array}$ \\
\hline$N$ & 542 & 542 & 542 \\
\hline$R^{2}$ & 0.153 & 0.150 & 0.288 \\
\hline $\begin{array}{l}\text { Robust standard errors } \\
\text { Note: All models inclu } \\
\text { maternal education (Re } \\
\text { household income, mate } \\
\text { household plus all varia } \\
\text { v27 (2001-2010). }\end{array}$ & $\begin{array}{l}\text { second row, }{ }^{*} p<0.1 \\
\text { as additional covari } \\
\text { category: vocational } \\
\text { al working hours, } p \\
\text { s used to predict me }\end{array}$ & $\begin{array}{l}{ }^{* *} p<0.05,{ }^{* * *} p \\
\text { regional unemplo } \\
\text { gree } \mid \text { university de } \\
\text { ner present, and } n \\
\text { rnal propensity sco }\end{array}$ & $\begin{array}{l}\text { 0.01. PS=propensity score. } \\
\text { ment rate, region (East=1, } \text {, } \\
\text { rree, no degree), logarithmic } \\
\text { mber of children }<16 \text { in the } \\
\text { es. Own calculations, SOEP }\end{array}$ \\
\hline
\end{tabular}

Similar to the preschool sample, maternal personality traits are included to control for unobserved heterogeneity. The significance of the effect of an experienced job loss on internal locus of control and the size of the effect increase from 22 per cent of standard deviation in Table 5 to 26 per cent of a standard deviation (see Table 6, column 3). Both, including maternal personality traits and applying a regression-adjusted matching approach, indicate that the findings are robust and suggest that the results could hint towards a causal relationship between maternal involuntary job loss and children's non-cognitive skills. 
Table 6: Estimations of internal locus of control under inclusion of maternal personality traits (adolescence sample)

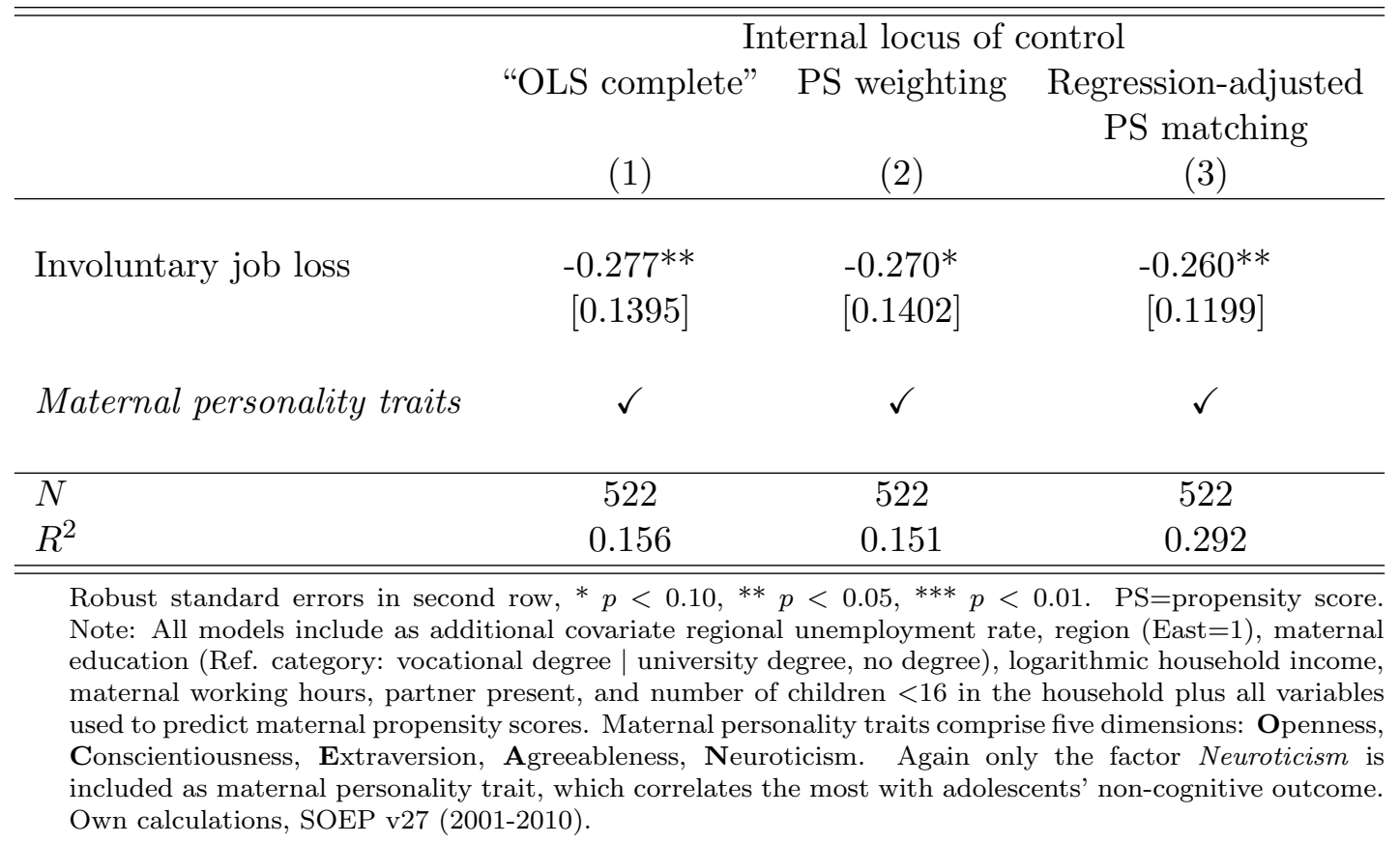

\section{Sensitivity analysis}

In order to relate my obtained results to the literature, this section presents additional estimations. First, I divide involuntary job loss into its two components: plant closure and dismissal by employer. This approach aims at comparing my findings to studies solely focusing on firm closure as a natural experiment. In a second step I provide estimates of non-cognitive skills and job loss including potential mediators, i.e., differences in income or in life satisfaction, in my analyses.

\subsection{Plant closure}

Compared to studies using a natural experiment approach the incidence of observing job loss due to plant closure in the SOEP is relatively small, which makes it impossible to match on plant closure incidences only. Although dismissal by employer is perceived to be exogenous in this paper, the strict definition of exogeneity applies to the incidence plant closure, meaning that maternal behavior cannot lead to firm downsizing. 
In Table 7 the results of post matching estimations of the relationship between internal locus of control and involuntary job loss distinguishing between plant closure and dismissal by employer are shown. In order to disentangle the overall job loss effect the relationship of children's non-cognitive skills and job loss is inferred by using job loss due to plant closure and due to dismissals as separate dummy variables instead of including the overall measure involuntary job loss in the analyses. The direction of the effect remains negative for both types of job loss, but the coefficient of plant closure is not statistically significant. The results indicate that job ends due to layoffs by employer have a significant effect on adolescents' internal locus of control. This could suggest that dismissals might be more closely related to mothers' emotional balance, which is assumed to be a potential mediator affecting children's outcomes. However by splitting the incidence of involuntary job loss, the coefficient of plant closure is bound to be insignificant as fewer mothers are exposed to firm closure compared to dismissals.

Table 7: Estimation of internal locus of control distinguishing on plant closure and dismissal by employer

\begin{tabular}{|c|c|c|}
\hline & \multicolumn{2}{|c|}{ Adolescence sample } \\
\hline & PS weighting & $\begin{array}{c}\text { Regression-adjusted } \\
\text { PS matching }\end{array}$ \\
\hline \multirow[t]{2}{*}{ Job loss due to plant closure } & -0.016 & -0.025 \\
\hline & {$[0.1828]$} & {$[0.1511]$} \\
\hline \multirow[t]{2}{*}{ Job loss due to dismissals } & $-0.373^{* *}$ & $-0.364^{* * *}$ \\
\hline & {$[0.1747]$} & {$[0.1381]$} \\
\hline$N$ & 542 & 542 \\
\hline$R^{2}$ & 0.153 & 0.299 \\
\hline \multicolumn{3}{|c|}{$\begin{array}{l}\text { Robust standard errors in second row, }{ }^{*} p<0.10,{ }^{*} p<0.05, * * * p<0.01 . \\
\text { PS=propensity score. Note: All models include as additional covariate regional } \\
\text { unemployment rate, region (East=1), maternal education (Ref. category: vocational } \\
\text { degree | university degree, no degree), logarithmic household income, maternal } \\
\text { working hours, partner present, and number of children }<16 \text { in the household plus all } \\
\text { variables used to predict maternal propensity scores. Own calculations, SOEP v27 } \\
(2001-2010) \text {. }\end{array}$} \\
\hline
\end{tabular}




\subsection{Estimations of non-cognitive skills considering possible mechanisms mediating involuntary job loss}

At the beginning of this paper potential mediators through which an involuntary job loss could affect children's non-cognitive skills are discussed. In order to test these complied hypotheses I compare changes in life satisfaction, changes in income, and changes in mother-child activities. By contrasting the observed means before and after the incidence of maternal involuntary job loss I assess potential directions through which mothers' experiences are linked with child outcomes.

In Table 8 a first descriptive examination shows the t-ratios of the mean comparison before and after treatment. In column 1 the differences in life satisfaction or in mother-child activities of treated mothers in the matched preschool sample are shown. Maternal life satisfaction significantly decreased for mothers who experience a job loss. A first mean comparison of differences in household income on the other hand does not render clear results for mothers who are exposed to a job end ${ }^{20}$. Indicating that household income is not significantly different after job loss. This could stem from husbands/partners that are still working and contributing to the overall household earnings. In addition, mothers of preschool children work less hours compared to mothers of older children, which leads to a "minor drop" in income. In column 2 the changes in life satisfaction for displaced mothers in the matched adolescence sample are shown.

Table 8: Underlying mechanisms: Comparing potential drivers before and after treatment $\left(\right.$ mean $\left(x_{\text {before }}\right)=$ mean $\left.\left(x_{\text {after }}\right)\right)$

\begin{tabular}{|c|c|c|}
\hline & $\begin{array}{c}\text { Preschool sample } \\
\text { t-ratio }\end{array}$ & $\begin{array}{c}\text { Adolescence sample } \\
\text { t-ratio }\end{array}$ \\
\hline Life satisfaction & $2.41^{* *}$ & 0.21 \\
\hline \multicolumn{3}{|l|}{ Mother-child activities } \\
\hline Going to the playground & -0.59 & - \\
\hline Reading stories & -0.43 & - \\
\hline$N$ & 14 & 64 \\
\hline
\end{tabular}

\footnotetext{
${ }^{20}$ Nonetheless, the multivariate analyses include the difference in household income pre and post treatment (see Table 9 and Table 10).
} 
This first descriptive glance at mothers' outcomes shows that mothers who are displaced report a significantly lower overall life satisfaction. They also read less often stories with their young children, yet this difference is not statistically significant (see Table 8). Interestingly for mothers of children aged seventeen the overall life satisfaction is not significantly different before and after displacement. This could suggest that mothers of young children are more stressed or frustrated about their job loss than mothers of older children. Yet mothers' own perception of life could be affected by involuntary job loss which might influence their children's beliefs. However in the SOEP the question on adults' locus of control is only surveyed in 2005 and 2010, so that a mean comparison before and after job loss cannot be applied. Instead I include mothers internal locus of control in the regression analysis beside maternal personality traits in order to account for this potential channel of discouragement.

In Table 9 the differences of potential mediators are included in the propensity score weighted regressions. Using the differences as covariates shows that a change in household income (see model (1)) or a change in life satisfaction (see model (2)) are not statistically significant. However, both mediators increase the overall sample fit indicating that they are explaining part of the variance of socio-emotional behavior. In addition by including differences in maternal life satisfaction the coefficient of involuntary job loss becomes statistically insignificant. The inclusion of mother-child activities decreases the sample size significantly (see column 4 of Table 9), as not all children are observed at age three and at age six. The relationship found in the descriptive statistics suggests that mothers' emotional balance might be affected, as maternal life satisfaction is significantly lower after involuntary job loss in the preschool sample (see Table 8). However, the evidence is not sufficient to completely support the emotional balance hypothesis, but it suggests that mothers are less satisfied after having lost their job. This could be a possible mediator of job loss. 
Table 9: Estimation of socio-emotional behavior including differences in life satisfaction, household income and mother-child activities (using PS weighting) (preschool sample)

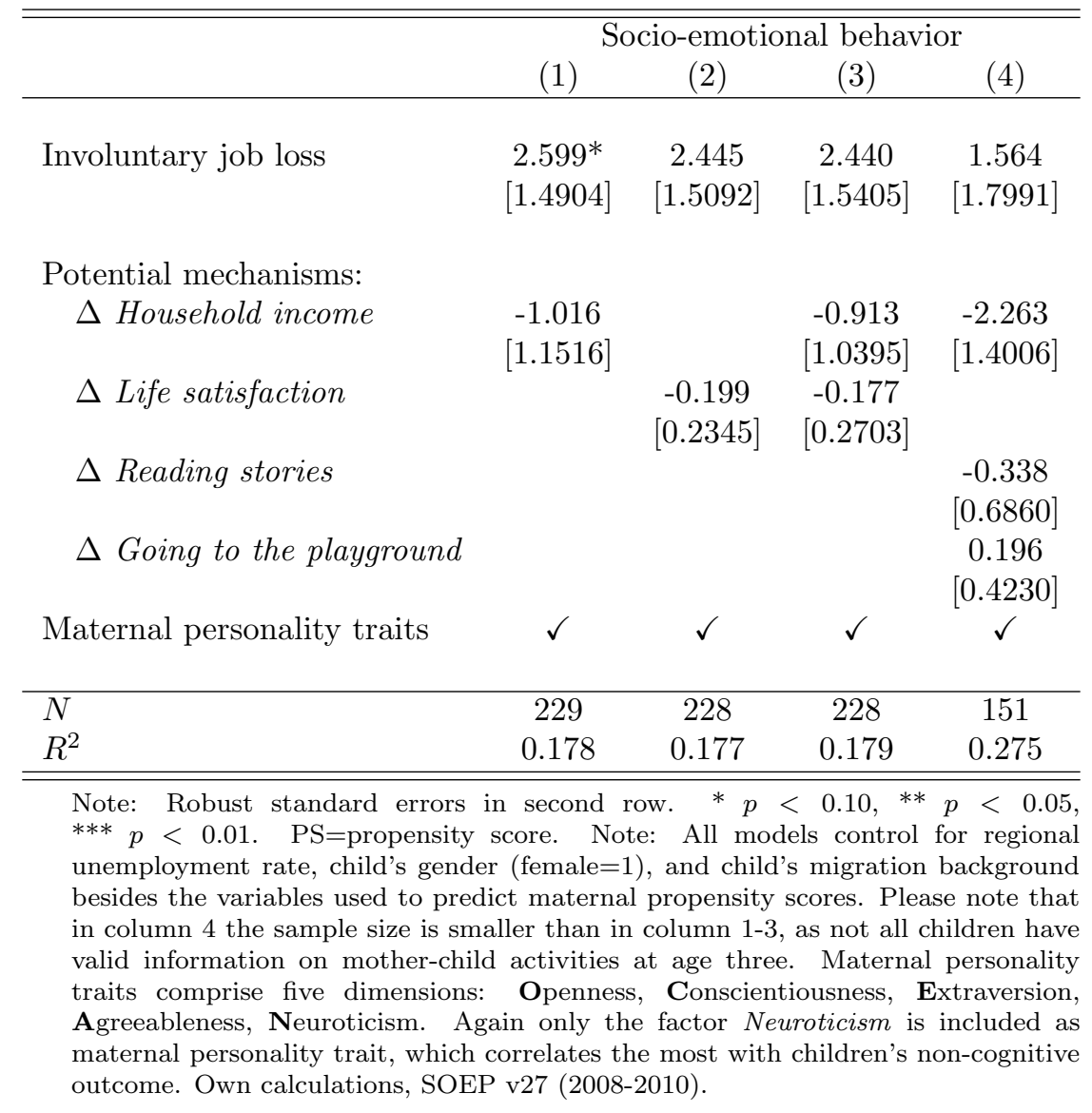

In the adolescence sample the crude measures used to address underlying mechanisms do not sufficiently disentangle potential mediator effects. In Table 10 it is shown that none of the differences included in the regression analyses are significantly explaining parts of the variance of adolescents' internal locus of control. In contrast to the preschool sample changes in household incomer or in maternal life satisfaction do not influence the correlation of involuntary job loss and non-cognitive skills of adolescents, as the estimates remain statistically significant. The hypothesis of emotionally imbalanced mothers may already be captured by maternal non-cognitive skills which are controlled for as well. Mothers' internal locus of control is significantly correlated with adolescents' beliefs in self-determination. In addition the effect of involuntary job loss on adolescents' outcome increases when maternal internal locus of control is included in the regression (see model 
(4)), suggesting that the measure of maternal locus of control might be spurious, as it is surveyed after job loss but not before.

Table 10: Estimation of internal locus of control including differences in life satisfaction, household income and maternal locus of control (using PS weighting) (adolescence sample)

\begin{tabular}{|c|c|c|c|c|}
\hline & \multicolumn{4}{|c|}{ Internal locus of control } \\
\hline & (1) & $(2)$ & $(3)$ & $(4)$ \\
\hline \multirow[t]{2}{*}{ Involuntary job loss } & $-0.266^{*}$ & $-0.267^{*}$ & $-0.261^{*}$ & $-0.296^{* *}$ \\
\hline & {$[0.1450]$} & {$[0.1400]$} & {$[0.1449]$} & {$[0.1373]$} \\
\hline \multicolumn{5}{|l|}{ Potential mechanisms: } \\
\hline \multirow[t]{2}{*}{$\Delta$ Household income } & -0.054 & & -0.043 & \\
\hline & {$[0.1652]$} & & {$[0.1651]$} & \\
\hline \multirow[t]{2}{*}{$\Delta$ Life satisfaction } & & -0.026 & -0.026 & \\
\hline & & {$[0.0320]$} & {$[0.0321]$} & \\
\hline \multirow[t]{2}{*}{ Maternal internal locus of control } & & & & $0.160^{* * *}$ \\
\hline & 1 & ( & 1 & {$[0.0459]$} \\
\hline Malermal persondinty ualls & $\checkmark$ & $\checkmark$ & $\checkmark$ & $\checkmark$ \\
\hline$N$ & 521 & 522 & 521 & 516 \\
\hline$R^{2}$ & 0.150 & 0.152 & 0.151 & 0.172 \\
\hline
\end{tabular}

Note: Robust standard errors in second row. $* p<0.10,{ }^{* *} p<0.05$,

$* * * p<0.01$. PS $=$ propensity score. Note that all models include as additional covariate regional unemployment rate, region (East=1), maternal education (Ref. category: vocational degree $\mid$ university degree, no degree), logarithmic household income, maternal working hours, partner present, and number of children $<16$ in the household plus all variables used to predict maternal propensity scores. Maternal personality traits comprise five dimensions: Openness, Conscientiousness, Extraversion, Agreeableness, Neuroticism. Again only the factor Neuroticism is included as maternal personality trait, which correlates the most with adolescents' non-cognitive outcome. Own calculations. SOEP v27 (2001-2010).

\section{Conclusion}

This paper analyzes the potential effect of maternal involuntary job loss on children's non-cognitive skills. An exogenous shock, such as an involuntary job loss, occurring to mothers might be more closely related to children's non-cognitive skills. Mothers' emotional balance could be negatively influenced by experiencing an involuntary job loss. By examining mothers life satisfaction before and after job loss, this paper aims at addressing potential mechanisms of job loss.

A potential problem for the analysis of maternal involuntary job loss on child outcomes is selection. Maternal job loss depends on maternal preferences, maternal 
background, available child care or on children's development which biases results obtained from OLS. Meaning that mothers whose children are more independent and socio-emotional "stable" are more likely to lose a job. Thus, mothers' displacement is not independent of children's skills. In this paper I therefore estimate the relationship between job loss and child outcomes addressing selection bias using propensity score methods. The propensity score method assumes that selection is based on observables which are used to match "similar mothers", i.e., in terms of observed characteristics, who do not experience a job loss with those who are exposed to plant closure or dismissal by employers.

This paper shows that experiencing maternal involuntary job loss during early childhood increases children's socio-emotional problems. Children are more likely to have peer problems or emotional problems. Children's total difficulties score increases by 3 score points, which lifts the mean child closer to "abnormal" behavior. The hypothesis that mothers substitute lost working time with more time for caring might not result in "better" quality of time due to stress or discouragement. I find descriptive evidence that mothers are less satisfied after experiencing a job loss and that they spend less time reading stories or going to the playground - suggesting a decrease in their emotional balance.

For adolescents an adverse effect of maternal job loss on non-cognitive skills is found. Children are less likely to believe in self-determination if their mother experienced an involuntary job loss due to plant closure or dismissal. The effect of maternal job loss is substantial, since adolescents internal locus of control decreases by $1 / 5^{t h}$ of a standard deviation using the propensity score method addressing selection bias. Including maternal personality traits in the analysis to account for unobserved heterogeneity confirms this negative result. The results become even more statistically significant indicating that an involuntary job loss "causes" adolescents to believe less in self-determination, in other words to be less motivated or striving for success.

When I distinguish between job loss due to plant closure and dismissal by employer in my analyses, the results show that mothers' job loss due to dismissal by employer is strongly correlated with children's non-cognitive outcomes. The findings from distinguishing between plant closure and layoffs should nonetheless be interpreted carefully, as plant closures are less frequently observed in the data.

The difference in maternal life satisfaction indicates that maternal frustration could be affecting the mother-child relationship. In addition, the negative association of maternal job loss and children's outcomes could be due to "mediocre" quality of time spent with children. The descriptive support for these potential mediators 
sheds some light on underlying mechanisms, but changes in income and in life satisfaction cannot completely explain the relationship between maternal job loss and children's non-cognitive skills, as the coefficient remains significant at least in the adolescence sample. In contrast to the preschool sample mothers life satisfaction remains unchanged due to job loss. Mothers' belief in self-determination is closely related to their children's outcome, yet this paper cannot test whether maternal locus of control changed due to experiencing a displacement. This paper therefore infers potential mediators only in a limited way suggesting that future research should address mechanisms linking parental job loss with children's outcomes (for a first study see: Wightman 2011).

The propensity score method suggests a potential causal relationship between children's non-cognitive skills and maternal involuntary job loss, since the estimates are consistent with the OLS results, yet provide smaller standard errors. Although the propensity score method reduces potential biases resulting from differences in mothers' characteristics, it cannot address selection on unobservables. But the findings remain robust after including maternal personality traits in the estimations. This paper argues that while maternal job loss might be beneficial for cognitive outcomes, i.e., grade point average (Rege et al. 2011), the association of job loss and non-cognitive skills differs. These negative effects of maternal involuntary job loss on non-cognitive skills might impede children's progress in school or on the labor market. Thus, further analyses regarding non-cognitive development and potential influences should be carried out.

With regards to policy implications, this paper shows that further research is necessary in order to disentangle potential influences of maternal job loss on children's non-cognitive skills. The evidence found in this paper indicates that financial support should not be the only means to help mothers who experience a displacement. For example job centers could provide additional help during job search for mothers, as mothers' overall life satisfaction decreases affecting the mother-child relationship. Supporting mothers to be less stressed or discouraged with job loss could be beneficial for their children.

\section{References}

Ashenfelter, O. (1978), 'Estimating the effect of training programs on earnings', Review of Economics and Statistics 60(1), 47-57. 
Baum II, C. L. (2003), 'Does early maternal employment harm child development? An analysis of the potential benefits of leave taking', Journal of Labor Economics 21(2), 381-408.

Baum II, C. L. (2004), 'The long-term effects of early and recent maternal employment on a child's academic achievement', Journal of Family Issues 25, 29-66.

Berger, E. M. \& Spiess, C. K. (2011), 'Maternal life satisfaction and child outcomes: Are they related?', Journal of Economic Psychology 32(1), 142-158.

Berger, L. M., Hill, J. \& Waldfolgel, J. (2005), 'Maternity leave, early maternal employment and child health and development in the US', The Economic Journal 115(501), F29-F47.

Bratberg, E., Nilsen, O. A. \& Vaage, K. (2008), 'Job losses and child outcomes', Labour Economics 15(4), 591-603.

Caliendo, M., Cobb-Clark, D. \& Uhlendorff, A. (2010), Locus of control and job search strategies, IZA Discussion Paper No. 4750, IZA, Bonn.

Caliendo, M. \& Kopeinig, S. (2008), 'Some practical guidance for the implementation of propensity score matching', Journal of Economic Surveys 22(1), 31-72.

Charles, K. K. \& Stephens, Jr, M. (2004), 'Job displacement, disability, and divorce', Journal of Labor Economics 22(2), 489-522.

Clark, A., Knabe, A. \& Raetzel, S. (2010), 'Boon or bane? Other's unemployment, well-being and job insecurity', Labour Economics 17(1), 52-61.

Coelli, M. B. (2011), 'Parental job loss and the education enrollment of youth', Labour Economics 18(1), 25-35.

Dehejia, R. \& Wahba, S. (2002), 'Propensity score matching methods for nonexperimental causal studies', Review of Economics and Statistics 84(1), 151-161.

Eliason, M. (2011), 'Income after job loss: the role of the family and the welfare state', Applied Economics 43(5), 603-618. First published on: 03 June 2009 (iFirst).

Eliason, M. \& Storrie, D. (2009), 'Job loss is bad for your health - swedish evidence on cause-specific hospitalization following involuntary job loss', Social Science $\&$ Medicine 68(8), 1396-1406. 
Ermisch, J. (2008), 'Origins in Social Immobility and Inequality: Parenting and Early Child Development', National Institute Economic Review 205(1), 62-71.

Frick, J. R. \& Lohmann, H. (2010), Biography and life history data in the German Socio-Economic Panel (SOEP, v26, 1984-2009), Data Documentation 52, DIW, Berlin.

Gebel, M. (2009), 'Fixed-term contracts at labour market entry in West Germany: Implications for job search and first job quality', European Sociological Review 25(6), 661-675.

Goodman, R. (1997), 'The strengths and difficulties questionnaire: A research note', Journal of Child Psychology and Psychiatry 38(5), 581-586.

Heckman, J. J., Ichimura, H. \& Todd, P. (1997), 'Matching as an econometric evaluation estimator: Evidence from evaluating a job training programme', Review of Economic Studies 64(4), 605-654.

Heineck, G. \& Anger, S. (2010), 'The returns to cognitive abilities and personality traits in Germany', Labour Economics 17(3), 535-546.

Hill, J. L., Waldfogel, J., Brooks-Gun, J. \& Han, W. J. (2005), 'Maternal employment and child development: A fresh look using newer methods', Developmental Psychology 41(6), 833-850.

Hirano, K. \& Imbens, G. (2001), 'Estimation of causal effects using propensity score weighting: An application to data on right heart catheterization', Health Services and Outcomes Research Methodology 2(3-4), 259-298.

Huff-Stevens, A. \& Schaller, J. (2011), 'Short-run effects of parental job loss on children's academic achievement', Economics of Education Review 30(2), 289-299.

Imbens, G. (2000), 'The role of the propensity score in estimating dose-response functions', Biometrika 86(1), 706-710.

James-Burdumy, S. M. (2005), 'The effect of maternal labor force participation on child development', Journal of Labor Economics 23(1), 177-211.

Jiang, M., Foster, E. M. \& Gibson-Davis, C. (2010), 'Breastfeeding and child cognitive outcomes: A propensity score matching approach', Maternal and Child Health Journal 5(8), 1296-1307.

Kalil, A. \& Ziol-Guest, K. M. (2008), 'Parental employment circumstances and children's academic progress', Social Science Research 37(2), 500-515. 
Knabe, A., Raetzel, S., Schoeb, R. \& Weimann, J. (2010), 'Dissatisfied with life but having a good day: Time-use and well-being of the unemployed', Economic Journal 120(547), 867-889.

LaLonde, R. (1986), 'Evaluating the econometric evaluation of training programs with experimental data', American Economic Review 76(4), 604-620.

Leuven, E. \& Sianesi, B. (2003), PSMATCH2: Stata module to perform full mahalanobis and propensity score matching, common support graphing, and covariate imbalance testing. http://ideas.repec.org/c/boc/bocode/s432001.html. This version 4.0.4 10nov2010.

Lindo, J. M. (2011), 'Parental job loss and infant health', Journal of Health Economics 30(5), 869-879.

Oreopoulos, P., Page, M. \& Huff Stevens, A. (2008), 'The intergenerational effect of worker displacement', Journal of Labor Economics 26(3), 455-483.

Rege, M., Telle, K. \& Votruba, M. (2011), 'Parental job loss and children's school performance', The Review of Economic Studies 78(3), 1-28.

Rege, M., Votruba, M. \& Kjetill, T. (2009), 'The effect of plant downsizing on disability pension utilization', Journal of the European Economic Association $7(4), 754-785$.

Rosenbaum, P. \& Rubin, D. (1983), 'The central role of the propensity score in observational studies for causal effects', Biometrika 70(1), 41-55.

Rosenbaum, P. \& Rubin, D. (1984), 'Reducing bias in observational studies: Using subclassifications on the propensity score', Journal of American Statistical Association 79(387), 516-524.

Rotter, J. B. (1966), 'Generalized expectancies for internal versus external control of reinforcement', Psychological Monographs: General and Applied 80(1), 1-28.

Rübennach, S. (2010), Alles beim Alten: Mütter stellen Erwerbstätigkeit hinten an, STATmagazin Arbeitsmarkt, Statistisches Bundesamt, Wiesbaden.

Ruhm, C. J. (2004), 'Parental employment and child cognitive development', Journal of Human Resources 39(1), 155-192.

Ruhm, C. J. (2008), 'Maternal employment and adolescent development', Labour Economics 15(5), 958-983. 
Ruhm, C. J. (2009), Maternal employment and child development, in D. R. Crane \& E. J. Hill, eds, 'Handbook of Families and Work', University Press of America, pp. 331-408.

Schupp, J., Spiess, C. K. \& Wagner, G. (2008), 'Die verhaltenswissenschaftliche Weiterentwicklung des Erhebungsprogramms des SOEP', Vierteljahreshefte zur Wirtschaftsforschung 77(3), 63-76.

Siedler, T., Schupp, J. \& Spiess, C. K. (2009), 'The German Socio-Economic Panel (SOEP) as Reference Data Set', Schmollers Jahrbuch 129(2), 367-374.

Smith, J. A. \& Todd, P. E. (2005), 'Does matching overcome LaLonde's critique of nonexperimental estimators?', Journal of Econometrics 125(1-2), 305-353.

Statistisches Bundesamt (2010), Alleinerziehende in Deutschland, Ergebnisse des Mikrozensus 2009, press release 29 July 2010., Statistisches Bundesamt, Wiesbaden.

Stuart, E. (2010), 'Matching methods for causal inference: A review and a look forward', Statistical Science 25(1), 1-21.

Wagner, G. G., Frick, J. R. \& Schupp, J. (2007), 'The German Socio-Economic Panel Study (SOEP) - Scope, evolution, and enhancements', Schmollers Jahrbuch 127(1), 139-169.

Waldfogel, J., Han, W.-J. \& Brooks-Gun, J. (2002), 'The effects of early maternal employment on child cognitive development', Demography 39(2), 369-392.

Wightman, P. (2011), Parental job loss, parental ability and children's edcuational attainment. mimeo. 


\section{Appendix}

Table A.1: Summary statistics of observables used for propensity score estimation and of additional explanatory variables used in the estimations (preschool sample)

\begin{tabular}{|c|c|c|c|c|c|c|}
\hline & \multicolumn{2}{|c|}{ All } & \multicolumn{2}{|c|}{ Job loss } & \multicolumn{2}{|c|}{ No job loss } \\
\hline & Mean & Std. dev. & Mean & Std. dev. & Mean & Std. dev. \\
\hline \multicolumn{7}{|l|}{ Pre-treatment explanatory variables: } \\
\hline Full time employed prior childbirth & 0.46 & 0.49 & 0.47 & 0.52 & 0.46 & 0.50 \\
\hline Part time employed prior childbirth & 0.23 & 0.42 & 0.33 & 0.49 & 0.22 & 0.41 \\
\hline Full time employed in the birth-year of child & 0.35 & 0.48 & 0.40 & 0.51 & 0.35 & 0.48 \\
\hline Part time employed in the birth-year of child & 0.23 & 0.42 & 0.27 & 0.46 & 0.22 & 0.42 \\
\hline Years of education around childbirth & 13.11 & 2.63 & 12.13 & 2.05 & 13.18 & 2.66 \\
\hline Partner present in birth-year of child & 0.92 & 0.27 & 0.80 & 0.41 & 0.93 & 0.26 \\
\hline Number of children $<16$ in $\mathrm{HH}$ in birth-year of child & 1.77 & 0.84 & 1.53 & 0.74 & 1.79 & 0.85 \\
\hline Logarithmic household income around childbirth & 7.98 & 0.45 & 7.81 & 0.51 & 7.99 & 0.45 \\
\hline Satisfaction with "only being mother" ( $1=$ not satisfied $)$ & 0.16 & 0.37 & 0.27 & 0.46 & 0.15 & 0.36 \\
\hline Living in East Germany in 1989 & 0.35 & 0.48 & 0.47 & 0.52 & 0.35 & 0.48 \\
\hline Living in East Germany & 0.32 & 0.47 & 0.40 & 0.51 & 0.31 & 0.46 \\
\hline Living in an urban area around childbirth & 0.30 & 0.46 & 0.33 & 0.49 & 0.30 & 0.46 \\
\hline Grandparent care around childbirth & 0.59 & 0.49 & 0.53 & 0.52 & 0.59 & 0.49 \\
\hline \multicolumn{7}{|l|}{ Age of mother at childbirth: } \\
\hline Age group $20-25$ & 0.07 & 0.25 & 0.13 & 0.35 & 0.06 & 0.25 \\
\hline Age group 25-30 & 0.32 & 0.47 & 0.33 & 0.49 & 0.32 & 0.47 \\
\hline Age group $35+$ & 0.27 & 0.44 & 0.13 & 0.35 & 0.26 & 0.47 \\
\hline Age of child (in months) & 69.16 & 4.09 & 69.40 & 3.52 & 69.15 & 4.14 \\
\hline \multicolumn{7}{|l|}{ Additional explanatory variables: } \\
\hline Gender of child (female $=1$ ) & 0.49 & 0.50 & 0.47 & 0.52 & 0.49 & 0.50 \\
\hline Migration background of child & 0.14 & 0.34 & 0.26 & 0.46 & 0.13 & 0.33 \\
\hline Regional unemployment rate & 9.33 & 4.07 & 9.49 & 4.55 & 9.32 & 4.04 \\
\hline$N$ & 234 & & 15 & & 219 & \\
\hline
\end{tabular}

Own calculations. SOEP 27v (2001-2010). 
Table A.2: Summary statistics of observables used for propensity score estimation and of additional explanatory variables used in the estimations (adolescence sample)

\begin{tabular}{|c|c|c|c|c|c|c|}
\hline & \multicolumn{2}{|r|}{ All } & \multicolumn{2}{|c|}{ Job loss } & \multicolumn{2}{|c|}{ No job loss } \\
\hline & Mean & Std. dev. & Mean & Std. dev. & Mean & Std. dev. \\
\hline \multicolumn{7}{|l|}{ Pre-treatment explanatory variables: } \\
\hline Full time employed at age six of child & 0.30 & 0.46 & 0.38 & 0.49 & 0.29 & 0.46 \\
\hline Part time employed at age six of child & 0.34 & 0.47 & 0.31 & 0.47 & 0.34 & 0.47 \\
\hline Working hours at age six of child & 20.66 & 17.27 & 22.59 & 18.21 & 20.41 & 17.15 \\
\hline Years of education at age six of child & 12.09 & 2.49 & 12.47 & 2.88 & 12.04 & 2.44 \\
\hline Partner present at age six of child & 0.93 & 0.25 & 0.92 & 0.27 & 0.94 & 0.25 \\
\hline Number of children $<16$ in $\mathrm{HH}$ at age six of child & 2.09 & 0.80 & 2.08 & 0.84 & 2.09 & 0.79 \\
\hline Logarithmic household income at age six of child & 7.29 & 1.83 & 6.76 & 2.27 & 7.36 & 1.75 \\
\hline Living in East Germany in 1989 & 0.37 & 0.48 & 0.48 & 0.50 & 0.35 & 0.48 \\
\hline Living in an urban area at age six of child & 0.30 & 0.46 & 0.22 & 0.42 & 0.31 & 0.46 \\
\hline Overall life satisfaction at age six of child & 6.99 & 1.61 & 6.53 & 1.55 & 7.05 & 1.61 \\
\hline Tenure at age six of child & 4.05 & 5.37 & 3.51 & 4.62 & 4.12 & 5.46 \\
\hline Size of firm at age six of child & 5.27 & 4.03 & 4.92 & 3.90 & 5.32 & 4.04 \\
\hline Age of mother at childbirth & 27.58 & 4.62 & 27.95 & 4.82 & 27.54 & 4.59 \\
\hline Age group $20-25$ & 0.28 & 0.45 & 0.28 & 0.45 & 0.27 & 0.45 \\
\hline Age group 30-35 & 0.21 & 0.41 & 0.25 & 0.44 & 0.21 & 0.41 \\
\hline Age group $35+$ & 0.08 & 0.27 & 0.06 & 0.24 & 0.08 & 0.27 \\
\hline Gender of child (female $=1$ ) & 0.47 & 0.49 & 0.55 & 0.50 & 0.46 & 0.49 \\
\hline Migration background of child & 0.16 & 0.37 & 0.16 & 0.37 & 0.16 & 0.37 \\
\hline \multicolumn{7}{|l|}{ Additional explanatory variables: } \\
\hline Regional unemployment rate & 12.71 & 5.70 & 13.91 & 5.69 & 12.55 & 5.69 \\
\hline Logarithmic household income & 7.88 & 0.46 & 7.74 & 0.39 & 7.89 & 0.47 \\
\hline Partner present & 0.88 & 0.32 & 0.84 & 0.37 & 0.89 & 0.31 \\
\hline Number of children $<16$ in $\mathrm{HH}$ & 1.47 & 0.64 & 1.36 & 0.52 & 1.48 & 0.65 \\
\hline Living in East Germany & 0.37 & 0.48 & 0.45 & 0.50 & 0.35 & 0.48 \\
\hline University degree (mother) & 0.24 & 0.42 & 0.28 & 0.45 & 0.23 & 0.42 \\
\hline No degree (mother) & 0.15 & 0.36 & 0.14 & 0.35 & 0.15 & 0.36 \\
\hline Maternal working hours & 28.37 & 15.09 & 27.06 & 17.89 & 28.54 & 14.71 \\
\hline$N$ & 560 & & 64 & & 496 & \\
\hline
\end{tabular}

Own calculations. SOEP 27v (1990-2010). 
Table A.3: Balance of covariates between treatment and control group (preschool sample)

\begin{tabular}{|c|c|c|c|c|}
\hline & \multicolumn{2}{|c|}{ Mean } & \multicolumn{2}{|c|}{ Bias } \\
\hline & Treated & Untreated & $\mid$ Bias $\mid$ & $\mathrm{p}>|\mathrm{t}|$ \\
\hline \multicolumn{5}{|c|}{ Full time employed - prior childbirth } \\
\hline Unmatched & 0.50 & 0.45 & 9.0 & 0.725 \\
\hline Matched & 0.47 & 0.51 & 8.2 & 0.827 \\
\hline \multicolumn{5}{|c|}{ Part time employed - prior childbirth } \\
\hline Unmatched & 0.31 & 0.23 & 18.0 & 0.462 \\
\hline Matched & 0.33 & 0.29 & 8.7 & 0.825 \\
\hline \multicolumn{5}{|c|}{ Full time employed } \\
\hline Unmatched & 0.47 & 0.36 & 22.7 & 0.350 \\
\hline Matched & 0.40 & 0.39 & 0.1 & 0.999 \\
\hline \multicolumn{5}{|c|}{ Part time employed } \\
\hline Unmatched & 0.24 & 0.22 & 2.4 & 0.921 \\
\hline Matched & 0.27 & 0.25 & 3.7 & 0.924 \\
\hline \multicolumn{5}{|c|}{ Years of education } \\
\hline Unmatched & 11.91 & 13.27 & 56.4 & 0.044 \\
\hline Matched & 12.13 & 12.16 & 1.3 & 0.969 \\
\hline \multicolumn{5}{|l|}{ Partnered } \\
\hline Unmatched & 0.76 & 0.94 & 48.2 & 0.010 \\
\hline Matched & 0.80 & 0.78 & 4.8 & 0.912 \\
\hline \multicolumn{5}{|c|}{ Logarithmic household income } \\
\hline Unmatched & 7.79 & 8.02 & 50.4 & 0.038 \\
\hline Matched & 7.81 & 7.81 & 1.1 & 0.978 \\
\hline \multicolumn{5}{|c|}{ Number of children $<16$} \\
\hline Unmatched & 1.53 & 1.75 & 27.8 & 0.298 \\
\hline Matched & 1.53 & 1.55 & 2.4 & 0.944 \\
\hline \multicolumn{5}{|c|}{ Living in East Germany 1989} \\
\hline Unmatched & 0.42 & 0.33 & 18.9 & 0.410 \\
\hline Matched & 0.47 & 0.45 & 3.1 & 0.936 \\
\hline \multicolumn{5}{|c|}{ Living in East Germany } \\
\hline Unmatched & 0.32 & 0.29 & 5.6 & 0.811 \\
\hline Matched & 0.40 & 0.38 & 3.7 & 0.926 \\
\hline \multicolumn{5}{|c|}{ Living in an urban community } \\
\hline Unmatched & 0.26 & 0.27 & 2.1 & 0.928 \\
\hline Matched & 0.33 & 0.33 & 1.0 & 0.981 \\
\hline \multicolumn{5}{|c|}{ Grandparent care } \\
\hline Unmatched & 0.53 & 0.58 & 10.6 & 0.668 \\
\hline Matched & 0.53 & 0.51 & 5.1 & 0.892 \\
\hline \multicolumn{5}{|c|}{ Satisfaction with being a mother } \\
\hline Unmatched & 0.24 & 0.17 & 15.8 & 0.499 \\
\hline Matched & 0.27 & 0.24 & 7.1 & 0.861 \\
\hline \multicolumn{5}{|c|}{ Aged $20-25$ at childbirth } \\
\hline Unmatched & 0.11 & 0.06 & 15.6 & 0.455 \\
\hline Matched & 0.13 & 0.11 & 6.7 & 0.881 \\
\hline \multicolumn{5}{|c|}{ Aged $30-35$ at childbirth } \\
\hline Unmatched & 0.42 & 0.29 & 25.7 & 0.258 \\
\hline Matched & 0.33 & 0.32 & 2.6 & 0.945 \\
\hline \multicolumn{5}{|c|}{ Aged $35+$ at childbirth } \\
\hline Unmatched & 0.16 & 0.29 & 31.7 & 0.217 \\
\hline & 0.13 & 0.17 & 9.2 & 0.779 \\
\hline \multicolumn{5}{|c|}{ Age of child (in months) } \\
\hline Unmatched & 69.53 & 69.19 & 8.8 & 0.726 \\
\hline Matched & 69.40 & 69.47 & 1.9 & 0.958 \\
\hline
\end{tabular}

Note: All variables are measured around child birth unless indicated otherwise. Own calculations. SOEP 27v (2001-2010). 
Table A.4: Balance of covariates between treatment and control group (adolescence sample)

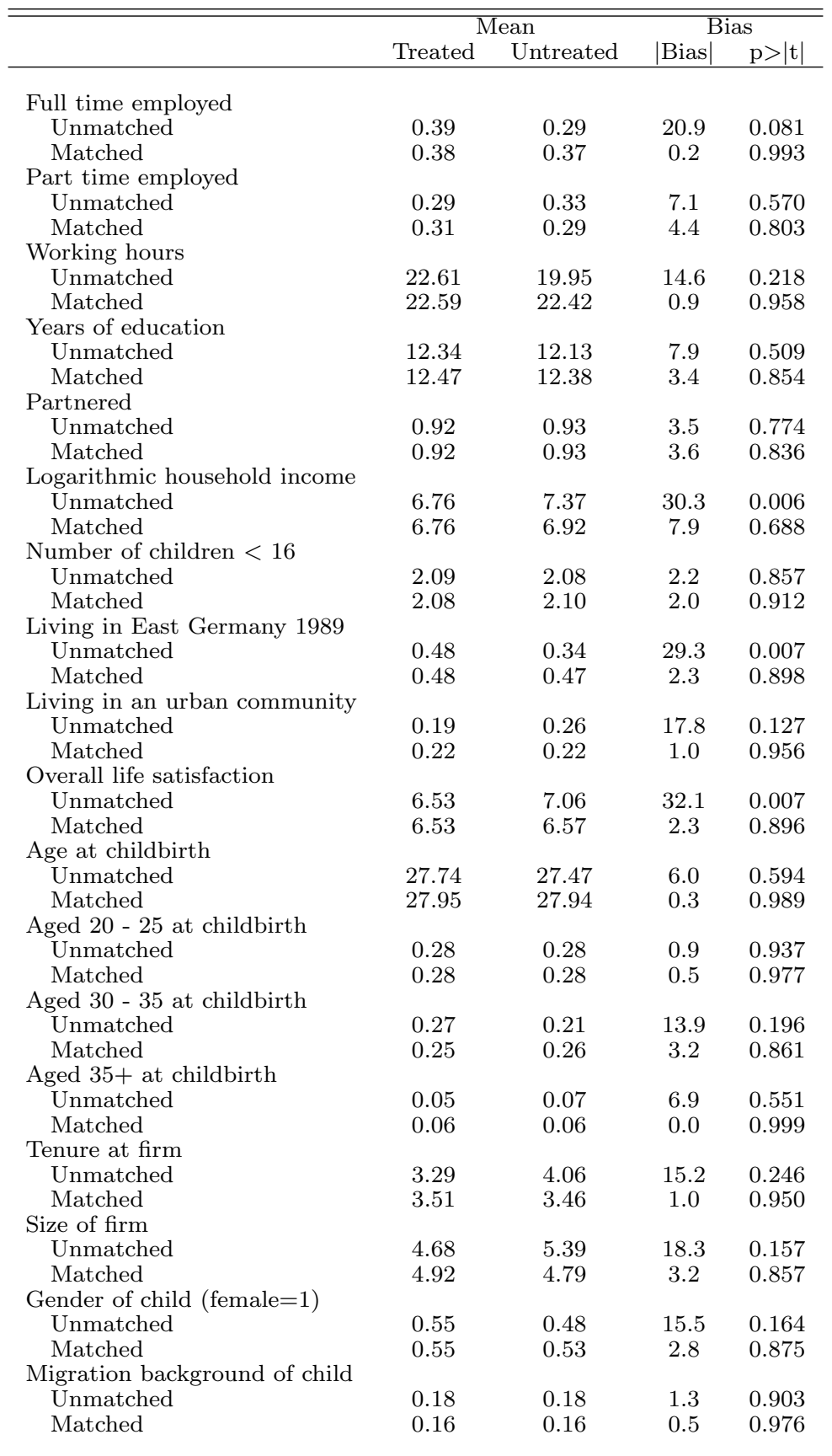

Note: All variables are measured at age six of child. Own calculations. SOEP 27v (1990-2010). 